\title{
Determinan Perempuan Keluar dari Praktik Kawin Anum Suku Banjar
}

\author{
Norma Yuni Kartika ${ }^{1}$, Muhajir Darwin², dan Sukamdi ${ }^{3}$ \\ 'Program Doktor Studi Kependudukan, Sekolah Pasca Sarjana, Universitas Gadjah Mada, \\ Yogyakarta, ${ }^{2}$ Fakultas IImu Sosial dan IImu Politik, Universitas Gadjah Mada, Yogyakarta, \\ ${ }^{3}$ Fakultas Geografi, Universitas Gadjah Mada, Yogyakarta
}

Korespondensi: Norma Yuni Kartika (e-mail: norma.yuni.k@mail.ugm.ac.id)

\begin{abstract}
Abstrak
"Kawin anum" dalam bahasa Banjar berarti perkawinan di bawah 16 tahun. Penelitian ini dilakukan di Kelurahan Raya Belanti, Kecamatan Binuang, Kabupaten Tapin, Provinsi Kalimantan Selatan dengan praktik kawin anum yang dipraktikkan oleh 90,26 persen penduduk perempuannya. Tujuan penelitian ini adalah mengetahui determinan perempuan keluar dari praktik kawin anum Suku Banjar. Penelitian ini menggunakan desain sequential explanatory method. Tahap pertama adalah melakukan survei terhadap 127 responden yang terdiri atas 37 perempuan yang menikah di bawah 16 tahun (pelaku kawin anum) dan 90 perempuan yang menikah pada usia 16-30 tahun, dan kemudian hasil analisis tahap pertama dieksplorasi lebih lanjut pada tahap kedua dengan metode kualitatif. Pada tahap kedua, informan dipilih berdasarkan hasil analisis tahap pertama dan 14 perempuan yang menolak desakan untuk segera menikah, 14 orang tua dan 9 stakeholders. Hasil penelitian ini menunjukkan bahwa terdapat empat variabel yang menjadi determinan perempuan keluar dari praktik kawin anum, yaitu variabel individual (berpendidikan tinggi dan bekerja), interpersonal (tingkat ekonomi keluarga asal perempuan tinggi), institusional (syarat menikah sudah memiliki kartu tanda penduduk) dan sosietal (memenuhi syarat usia minimal resmi yang diijinkan untuk menikah menurut undang-undang perkawinan).
\end{abstract}

Kata kunci: determinan; perempuan; keluar; kawin anum 


\title{
Determinants Women Out of Kawin Anum Practices in Banjar Tribe
}

\begin{abstract}
Kawin anum in local languange of Banjar means that a marriage conducted those who are under 16 years old. The research of kawin anum is located in Raya Belanti Village, Binuang District, Tapin District, South Kalimantan Province where kawin anum was practiced by 90.26 percent of female residents. The purpose of this study was to find out the determinants of women who got out of kawin anum practice in Banjar Tribe. This study uses a sequential explanatory method design. The first stage was conducting a survey to 127 respondents, consisted of 37 women married under 16 (perpetrators of kawin anum) and 90 women who were married at the age of 16-30 years. The results of first phase of analysis were further explored in the second stage using a qualitative method. For the second stage, the informants were chosen based on the results of the first phase analysis and 14 women who refused the urge to get married immediately, 14 parents and 9 stakeholders were selected. The results showed that there were four variables which were the determinants of women getting out of kawin anum practices, namely individual variables (highly educated and working women), interpersonal (women came from families with high level of economy), institutional (to get married, one must had an identification card) and societal (has fulfiled the minimum legal age requirements in order to be permitted to marry according to marriage law).
\end{abstract}

Keywords: determinants; women; getting out of; kawin anum

\section{Pendahuluan}

Fenomena perkawinan usia dini, perkawinan anak, dan perkawinan paksa di beberapa negara pada skala global atau beberapa provinsi khusus di Indonesia sudah berlangsung lama. Fenomena tersebut ada yang telah mengalami transisi yang tercermin dengan usia kawin pertama yang semakin dewasa dan ada yang masih langgeng yang telah membudaya hingga sekarang. Dampak dari perkawinan usia dini, perkawinan anak, dan perkawinan paksa adalah merugikan pihak perempuan, laki-laki, anak yang dilahirkan maupun keluarga, bahkan dampaknya lebih luas dari semua itu hingga merambah ke masyarakat, pemerintah dan negara.
Riset mengenai usia kawin pertama telah dilakukan dari berbagai dimensi, antara lain budaya, perilaku, kependudukan, sosial, psikologis, kesehatan, dan ekonomi. Hal tersebut dilandasi oleh pemikiran bahwa usia kawin pertama menjadi isu yang penting dalam kebijakan kependudukan. Pentingnya usia perkawinan pertama berhubungan dengan pengendalian jumlah penduduk melalui pengaturan kelahiran. Selain itu, usia kawin pertama juga merupakan variabel penting dalam keluarga berencana dan kesehatan reproduksi.

Permasalahan yang sangat penting mengenai usia kawin pertama adalah tingginya insiden pernikahan usia dini. Berdasarkan data Profil Anak Indonesia 2018 (KPPPA dan BPS, 2018), yang dimaksud dengan 


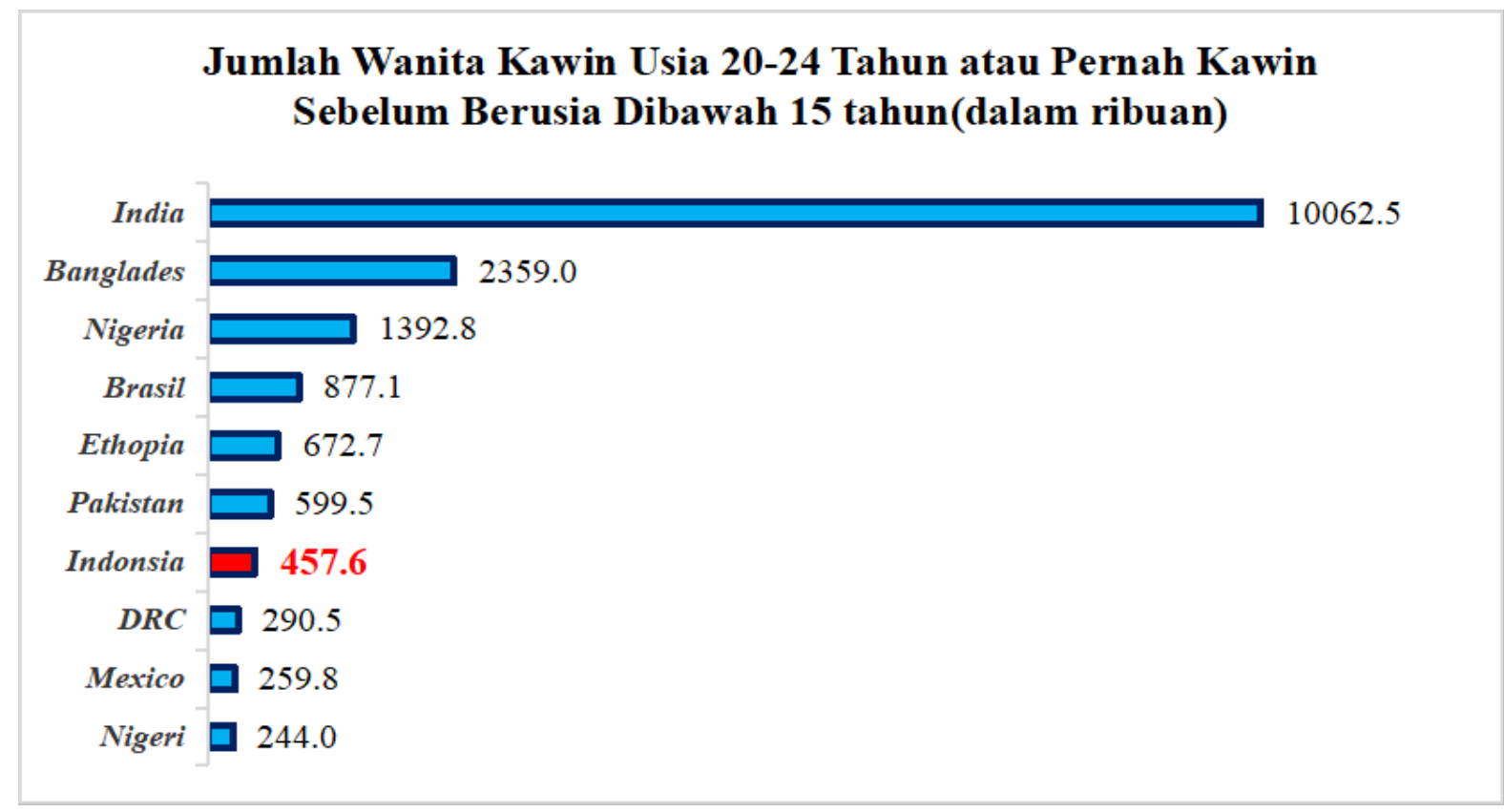

Sumber: Statistics and Monitoring Section, Division of Policy and Strategy (UNICEF, 2013; dalam KPPPA dan BPS, 2018)

Gambar 1. Jumlah Wanita Kawin Usia 20-24 Tahun atau Pernah Kawin sebelum Berusia di bawah 15 tahun

perkawinan usia anak adalah perkawinan yang dilakukan oleh anak di bawah 18 tahun. Pada kenyataannya, masih banyak dijumpai anak-anak di bawah 15 tahun yang telah melakukan pernikahan, bahkan mengalami perceraian. Indonesia merupakan negara dengan angka perkawinan sebelum usia 15 tahun tertinggi ketujuh di dunia setelah India, Bangladesh, Nigeria, Brasil, Ethiopia, dan Pakistan (Gambar 1).

Sebenarnya secara normatif, telah muncul regulasi yang mengatur tentang batas usia kawin. Usia resmi minimal menikah di Indonesia yang tertuang pada Pasal 7 ayat (1) Undang-Undang Perkawinan No. 1 Tahun 1974 sebelum adanya perubahan menjadi Undang-Undang Perkawinan No. 16 Tahun 2019 menjelaskan bahwa diizinkannya perkawinan oleh orang tua jika sekurang- kurangnya pihak laki-laki telah berusia 19 dan pihak perempuan berusia 16. Pasal ini sangat kontroversial sebab batasan tersebut secara tidak langsung melegalisasi praktik perkawinan usia anak. Pada sisi yang lain batasan tersebut merupakan suatu bentuk pelanggaran hak karena anak terlalu muda untuk membuat keputusan tentang pasangan perkawinan mereka atau tentang implikasi dari perkawinan itu sendiri.

Salah satu isu besar terkait dengan tingginya insiden perkawinan anak adalah aspek kultural. Aspek kultural menjadi penyebab langgengnya praktik perkawinan usia anak di Indonesia karena masih ada sebagian masyarakat yang menganggap bahwa semakin cepat menikah semakin baik bagi seorang perempuan. Dari sisi budaya, di beberapa daerah di Indonesia, khususnya 
daerah terpencil, menikah di usia muda adalah hal yang umum dilakukan dan bukan hal yang tabu meskipun tidak sesuai dengan ketetapan undang-undang perkawinan (KPPPA dan BPS, 2018). Hal ini tercermin dari Gambar 1 dimana terdapat 457,6 ribu perempuan Indonesia usia 20-24 tahun yang menikah sebelum berusia 15 tahun dan hal tersebut melanggar usia resmi minimal untuk menikah menurut undang-undang perkawinan.

Undang-Undang No. 16 Tahun 2019 tentang perubahan atas Undang-Undang No. 1 Tahun 1974 tentang Perkawinan konsisten dengan Undang-Undang Nomor 35 Tahun 2014 tentang Perubahan atas UndangUndang Nomor 23 Tahun 2002 tentang Perlindungan Anak pasal 1 ayat (1) yang di dalamnya menjelaskan bahwa anak adalah seseorang yang belum berusia 18 (delapan belas) tahun. Hal itu berarti usia minimal perempuan menikah pada Undang-Undang Perkawinan, yaitu 19 tahun, baik laki-laki maupun perempuan, tidak termasuk usia anak menurut Undang-Undang Perlindungan Anak. Dalam Undang-Undang Perlindungan Anak pasal 26 ayat 1 huruf $\mathrm{c}$ disebutkan bahwa orang tua berkewajiban dan bertanggung jawab untuk mencegah terjadinya perkawinan usia anak.

Implikasi perkawinan usia anak pada umumnya dialami lebih banyak oleh perempuan dibandingkan dengan laki-laki. Beberapa implikasinya adalah pada kesehatan reproduksi, intelektual, kualitas keluarga, psikologis dan psikososial, keharmonisan keluarga, perceraian, kawin ulang, pelanggaran hak anak, serta perempuan (Kasto, 1982; Santhya, 2010; PSKK UGM dan PLAN, 2011; BPS dan UNICEF, 2016; KPPPA dan BPS, 2018). Berdasarkan data BPS (2017) diketahui bahwa persentase perempuan berumur 20-24 tahun yang pernah kawin yang umur perkawinan pertamanya di bawah 18 tahun menurut Provinsi Tahun 2017 tertinggi adalah provinsi Kalimantan Selatan, yaitu 39,53 persen (Gambar 2).

Tingginya kasus perkawinan usia anak di Kalimantan Selatan berkaitan dengan praktik kawin anum yang masih dipraktikkan oleh sebagian besar masyarakat Suku Banjar. Praktik kawin anum pada suku Banjar merupakan faktor yang melanggengkan perkawinan usia anak. Kawin anum adalah perkawinan pertama yang dilakukan seseorang di bawah usia 16 tahun. Tingginya persentase perkawinan usia anak menurut hasil penelitian Nasution (2016) disebabkan oleh praktik kawin anum pada suku Banjar, antara lain karena orang tua ingin cepat menikahkan anaknya supaya anak mereka tidak disebut bujang tua.

Dari 924 pasangan usia subur di Kelurahan Raya Belanti, terdapat 90,26 persen perempuan yang menikah di bawah 16 tahun atau menjadi pelaku praktik kawin anum dan hanya 9,74 persen yang menikah di atas 16 tahun. Tingginya kasus kawin anum di Kelurahan Raya Belanti menyebabkan hanya ada 1 dari 10 perempuan yang tidak mempraktikkan kawin anum. Hal itu membawa konsekuensi negatif yang harus diemban tidak hanya perempuan tersebut, tetapi juga keluarga, masyarakat, dan pemerintah.

Kawin anum yang dipraktikkan oleh masyarakat di Kelurahan Raya Belanti, Kecamatan Binuang, Kabupaten Tapin, Provinsi Kalimantan Selatan merupakan pelanggengan terhadap praktik perkawinan usia anak yang membuat tujuan ke lima Sustainable Development Goals (SDGs), yakni tercapainya kesetaraan gender dan memberdayakan semua perempuan dan anak perempuan dengan target yaitu terhapusnya segala praktik yang membahayakan seperti 


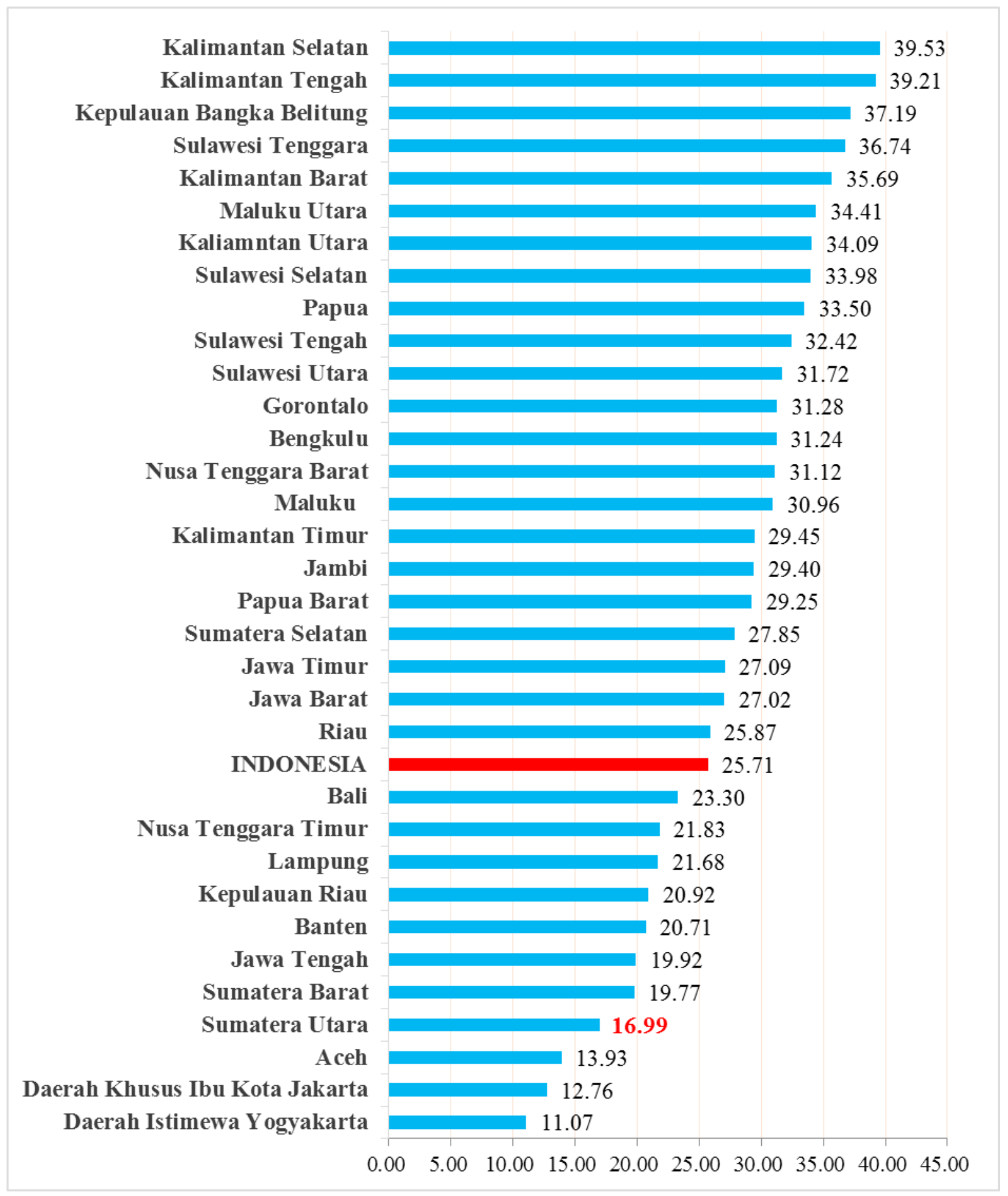

Sumber: BPS (2017)

Gambar 2. Persentase Perempuan Berumur 20-24 Tahun yang Pernah Kawin yang Umur Kawin Pertamanya di Bawah 18 Tahun menurut Provinsi Tahun 2017 
perkawinan anak sulit terwujud. Di antara mayoritas perempuan yang mempraktikkan kawin anum di Kelurahan Raya Belanti, terdapat perempuan-perempuan yang mampu keluar dari praktik kawin anum. Insiden perempuan yang mampu keluar dari praktik kawin anum ini belum pernah diteliti, sehingga hal ini menarik untuk dikaji lebih dalam terkait determinan perempuan keluar dari praktik kawin anum yang ada di daerahnya.

Penelitian ini menggunakan teori social ecological framework untuk menjelaskan determinan perempuan keluar dari praktik kawin anum suku Banjar.Teori Social Ecological Framework (SEF) adalah pengembangan dari teori ekologi Bronfenbrenner yang dikemukakan oleh Urie Bronfenbrenner. Teori ini digunakan untuk mengidentifikasi multiple factors yang memengaruhi penerimaan dan perilaku individu (Mc Leroy, et al., 1988). Kerangka Social-ecological Framework memiliki lima tingkatang (level), yaitu (1) The individual level (level individu), yaitu pengetahuan dan sikap tentang sesuatu, termasuk faktorfaktor biologi; (2) The interpesonal level (level interpersonal), yaitu hubungan dan pengaruh orang lain; (3) The community level (level masyarakat), termasuk norma-norma sosial dan jaringan sosial; (4) The institutional level (level institusi), yang menyangkut peraturanperaturan, regulasi dan struktur institusi dan organisasi yang berpengaruh terhadap seseorang untuk memilih atau berperilaku yang spesifik berkaitan dengan suatu isu atau situasi terkait isu tertentu; (5) The societal level (level negara), yang menyangkut kebijakan suatu negara yang memengaruhi perilaku seseorang. Multiple factors dalam teori social ecology framework pada penelitian ini mampu menjelaskan perilaku perempuan untuk keluar dari praktik kawin anum yang terdiri atas lima level. Dua level di antaranya adalah society dan institusional yang berhubungan dengan kebijakan dan undang-undang perkawinan yang ada di Indonesia, serta tiga level lainnya merupakan faktor eksternal maupun internal yang memengaruhi keputusan perempuan,

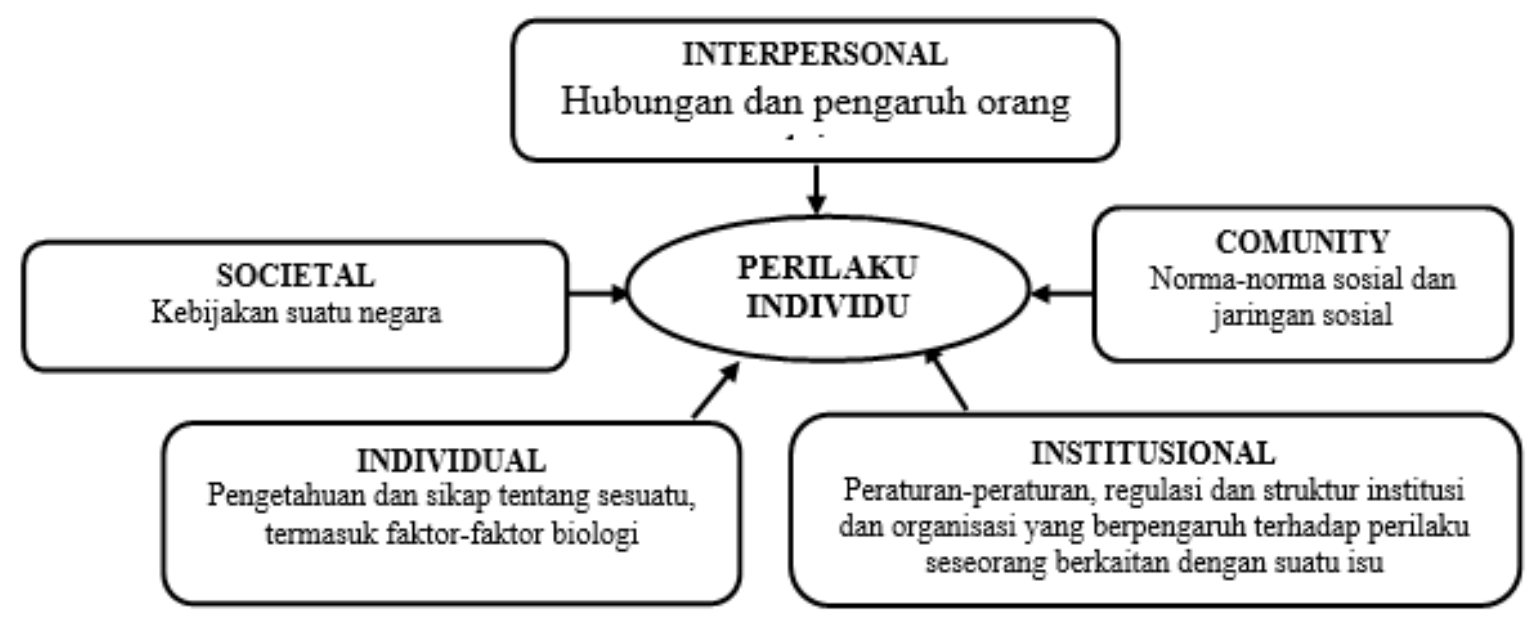

Sumber: Mc Leroy, et.al., 1988

Gambar 3. Kerangka Teori Sosial Ecologi Framework 
sehingga akhirnya keluar dari praktik kawin anum.

\section{Metode}

Explanatory sequential mixed methods (Creswell, 2010) adalah metode yang digunakan dalam kajian ini. Penelitian terdiri atas dua tahap, yaitu tahap pertama menggunakan metode survei, dan tahap kedua menggunakan metode kualitatif. Pada metode survei, seluruh perempuan yang memenuhi kriteria dijadikan responden. Responden dalam penelitian ini berjumlah 127, yang terbagi dalam dua kriteria, yaitu
: (1) perempuan dengan usia perkawinan pertama di bawah 16 tahun sebanyak 90 responden, (2) perempuan dengan usia perkawinan pertama 16-30 tahun sebanyak 37 responden. Instrumen yang digunakan berupa kuesioner.

Dalam penelitian ini, usia kawin pertama dibagi menjadi dua kategori, yaitu dibawah 16 tahun dan 16-30 tahun. Penentuan rentang usia kawin pertama di bawah 16 tahun disebut juga praktik kawin anum. Sedangkan, usia perkawinan pertama 16-30 dalam penelitian ini berdasarkan pertimbangan bahwa usia 16 tahun ke atas sudah bukan merupakan kawin anum dan batas 30 tahun disesuaikan

\section{Tabel 1. Hasil Uji Chi-Square Variabel yang Mempengaruhi Perempuan Keluar dari Praktik Kawin Anum}

\begin{tabular}{|c|c|c|c|c|c|c|c|c|c|}
\hline \multirow[t]{3}{*}{ No } & \multirow[t]{3}{*}{ Variabel } & \multicolumn{4}{|c|}{ Tipe Perkawinan } & \multirow{3}{*}{$\begin{array}{l}\text { Nilai X² } \\
\text { Hitung }\end{array}$} & \multirow[t]{3}{*}{ Df } & \multirow{3}{*}{$\begin{array}{c}\text { Nilai } \\
\mathrm{X}^{2} \\
\text { Tabel }\end{array}$} & \multirow{3}{*}{$\begin{array}{l}\text { Nilai } \\
\text { Sig. }\end{array}$} \\
\hline & & \multicolumn{2}{|c|}{$\begin{array}{c}\text { Keluar dari } \\
\text { praktik Kawin } \\
\text { Anum }\end{array}$} & \multicolumn{2}{|c|}{$\begin{array}{l}\text { Kawin } \\
\text { Anum }\end{array}$} & & & & \\
\hline & & $\mathbf{n}$ & $\%$ & $\mathbf{n}$ & $\%$ & & & & \\
\hline & $\begin{array}{l}\text { Daerah Asal } \\
\text { Penduduk Asli } \\
\text { Pendatang }\end{array}$ & $\begin{array}{l}70 \\
20\end{array}$ & $\begin{array}{l}77,78 \\
22,22\end{array}$ & $\begin{array}{r}32 \\
5\end{array}$ & $\begin{array}{l}68,49 \\
13,51\end{array}$ & 1,258 & 1 & 3,84 & 0,262 \\
\hline 2. & $\begin{array}{l}\text { Pendidikan } \\
\text { Tamat SD } \\
\text { Tamat SMP }\end{array}$ & $\begin{array}{l}43 \\
47\end{array}$ & $\begin{array}{l}47,78 \\
52,22\end{array}$ & $\begin{array}{r}32 \\
5\end{array}$ & $\begin{array}{l}86,49 \\
13,51\end{array}$ & $16,248^{*}$ & 1 & 3,84 & $0,000^{*}$ \\
\hline 3. & $\begin{array}{l}\text { Kegiatan Utama } \\
\text { Bekerja } \\
\text { Tidak Bekerja }\end{array}$ & $\begin{array}{l}60 \\
30\end{array}$ & $\begin{array}{l}66,67 \\
33,33\end{array}$ & $\begin{array}{l}17 \\
20\end{array}$ & $\begin{array}{l}45,95 \\
54,05\end{array}$ & $4,716^{*}$ & 1 & 3,84 & $0,030^{*}$ \\
\hline 4. & $\begin{array}{l}\text { Tingkat Ekonomi } \\
\text { RT Asal } \\
\text { Rendah } \\
\text { Sedang } \\
\text { Tinggi }\end{array}$ & $\begin{array}{l}20 \\
53 \\
17\end{array}$ & $\begin{array}{l}22,22 \\
58,89 \\
18,89\end{array}$ & $\begin{array}{r}20 \\
9 \\
8\end{array}$ & $\begin{array}{l}54,05 \\
24,32 \\
21,62\end{array}$ & $14,952^{*}$ & 2 & 5,99 & $0,001^{*}$ \\
\hline 5. & $\begin{array}{l}\text { Pekerjaan KRT } \\
\text { Pertanian } \\
\text { Non Pertanian }\end{array}$ & $\begin{array}{l}65 \\
25\end{array}$ & $\begin{array}{l}72,22 \\
27,78 \\
\end{array}$ & $\begin{array}{r}33 \\
4 \\
\end{array}$ & $\begin{array}{l}89,19 \\
10,81\end{array}$ & 4,284 & 1 & 3,84 & 0,038 \\
\hline
\end{tabular}

Sumber: Data Primer, 2017 
Tabel 2. Hasil Analisis Uji Regresi Logistik Linier Variabel yang Mempengaruhi Perempuan Keluar dari Praktik Kawin Anum

\begin{tabular}{lcr}
\hline \multicolumn{1}{c}{ Variabel } & Odds Ratio (OR) & Koefisien (B) \\
\hline Pendidikan & 7,1 & 1,961 \\
Kegiatan Utama & 3,1 & 1,128 \\
Tingkat Ekonomi Rumah Tangga & 1,4 & 0,351 \\
Asal & & \\
$\mathrm{R}^{2}$ & 0,261 & \\
Nilai Signifikan (P) & 0,000 & \\
\hline
\end{tabular}

Sumber: Data Primer, 2017

dengan saran BKKBN untuk usia reproduksi terbaik perempuan, yaitu maksimal 30 tahun untuk hamil dan bersalin.

Informan pada tahap kualitatif dipilih berdasarkan hasil survei, terdiri atas (1) empat belas perempuan yang menolak desakan untuk segera menikah, (2) empat belas orang tua perempuan yang menolak desakan untuk segera menikah, (3) sembilan stakeholders terkait tema penelitian. Data penelitian kualitatif menggunakan beragam sumber data yaitu indept interview, observasi, dan data sekunder. Analisis metode kuantitatif dilakukan secara deskriptif analitis dengan menggunakan chi-square dan uji regresi logistik linier. Analisis metode kualitatif digunakan untuk memperdalam analisis data kuantitatif.

\section{Pembahasan}

Dalam penelitian ini dilakukan uji statistik chi square untuk melihat ada tidaknya perbedaan antara variabel bebas, yaitu faktor yang mempengaruhi perempuan keluar dari praktik kawin anum (daerah asal, pendidikan, kegiatan utama, tingkat ekonomi rumah tangga asal perempuan dan pekerjaan kepala rumah tangga) dengan variabel terikat (keluar dari praktik kawin anum). Uji chi-square $\left(X^{2}\right)$ dalam penelitian ini dengan tingkat kemaknaan $\mathrm{X}^{2}$ tabel $<0,005$.

Berdasarkan Tabel 1, pendidikan, kegiatan utama, dan tingkat ekonomi rumah tangga asal perempuan mempunyai perbedaan bermakna terhadap perempuan yang keluar dari praktik kawin anum. Variabel daerah asal menunjukkan nilai chi-square hasil perhitungan lebih besar dari harga kritik, sehingga tidak terdapat perbedaan bermakna dengan perempuan yang keluar dari praktik kawin anum. Pekerjaan kepala rumah tangga tidak memenuhi persyaratan uji chisquare karena nilai frekuensi harapan kurang dari 5. Selanjutnya, variabel pendidikan, kegiatan utama dan tingkat ekonomi rumah tangga asal perempuan di uji menggunakan analisis regresi logistik linier dengan tingkat kemaknaan $p<0,005$ (Tabel 2).

Berdasarkan nilai $R^{2}$ pada Tabel 2, diketahui bahwa variabel pendidikan, kegiatan utama dan tingkat ekonomi rumah tangga asal perempuan menyebabkan perempuan keluar dari praktik kawin anum Suku Banjar 
sebesar 26,1 persen. Hasil uji regresi logistik linier memberikan gambaran nyata dan teruji bahwa perempuan yang lulus SMP, bekerja dan berasal dari rumah tangga dengan ekonomi tinggi menyebabkan perempuan keluar dari praktik kawin anum.

\section{Individual}

\section{a. Pendidikan}

Perempuan dengan pendidikan lulus SMP, 7,1 kali cenderung mampu keluar dari praktik kawin anum (Tabel 2). Semakin tinggi capaian pendidikan perempuan akan semakin tinggi usia kawin pertamanya. Semakin lama perempuan berada dalam bangku sekolah, akan semakin mampu mereka untuk keluar dari praktik kawin anum. Temuan ini sejalan dengan hasil penelitian-penelitian di Indonesia, seperti oleh Sukamdi, Yuarsi, dan Tamtiari (1997), Choe, et.al. (2001), PSKK UGM dan PLAN (2011), Indrayani dan Sjafii (2012), Utina, dkk. bekerja sama dengan BKKBN dengan IPADI (2014), BPS (2017), KPPPA dan BPS (2018) mendukung hipotesis yang dikemukakan oleh Bogue, Yaukey dan Thorsen, dan Smith. Hipotesis tersebut menunjukkan bahwa pendidikan merupakan faktor yang cukup dominan dalam menentukan usia kawin seorang perempuan. Dalam penelitian ini, pendidikan merupakan faktor utama yang mampu membuat perempuan keluar dari praktik kawin anum.

Salah satu solusi agar perempuan keluar dari praktik kawin anum adalah dengan pencapaian program wajib belajar dua belas tahun yang bertujuan untuk menekan berbagai perbedaan alami dari kelompok masyarakat yang ada, seperti perbedaan gender, karakteristik wilayah, tingkat ekonomi, etnik, agama, status sosial, dan budaya. Asumsinya, jika perempuan mampu mencapai wajib belajar dua belas tahun berada di bangku sekolah dari usia 16 hingga 18 tahun, sehingga tidak akan mempraktikkan kawin anum. Pendidikan diharapkan dapat menghilangkan semua perbedaan itu. Tujuan wajib belajar yang tercantum pada pasal 2 ayat (2) Peraturan Pemerintah Republik Indonesia Nomor 47 tahun 2008 adalah memberikan pendidikan minimal bagi warga negara Indonesia untuk dapat mengembangkan potensi dirinya agar dapat hidup mandiri dalam masyarakat atau melanjutkan pendidikan ke jenjang yang lebih tinggi.

Apabila program wajib belajar pendidikan dasar dua belas tahun sukses dan dapat diakses oleh semua masyarakat tanpa memandang gender, perbedaan karakteristik wilayah, strata ekonomi, etnik, agama, sosial, dan budaya, diharapkan usia perkawinan dapat ditunda. Dalam penelitian Sukamdi, Yuarsi dan Tamtiari (1995), jika banyak anak masuk sekolah di tingkat SMA, maka mereka akan mendapat pengetahuan mengenai keluarga dan kesehatan reproduksi sehingga semakin banyak anak yang mengerti tentang kesehatan reproduksi dan hak-haknya. Dengan pengetahuan yang diperoleh di sekolah, mereka diharapkan dapat menunda usia perkawinan pertama hingga mencapai usia dewasa secara fisik, psikologi, dan ekonomi. Berikut adalah ungkapan dari informan perempuan satu-satunya yang keluar dari praktik kawin anum dengan pendidikan sebelum menikah sarjana (S1).

“...kada handak lakas kawin kaya kekawanan, makanya bepadah lawan kuitan handak kuliah. Alhamdulillah diizinakan. Imbah lulus MAN lalu ae kuliah di Banjarbaru. Sengaja kuliah maraga takutan mun imbah tuntung MAN kena 
dikawinakan. Rancak sudah menolak orang bedatang, kena dikira orang kehaharatan, baik kuliah sama sekali". (....tidak ingin cepat menikah seperti teman-teman, makanya bilang dengan orangtua pengen kuliah. Alhamdulillah diizinkan. Setelah lulus MAN kemudian kuliah di Banjarbaru. Sengaja memilih kuliah karena takut setelah lulus MAN nanti dinikahkan. Sudah sering menolak orang melamar, nanti dikira orang sombong, lebih baik kuliah).

Pendidikan berpengaruh terhadap
perilaku manusia sehingga manusia
bersedia meninggalkan kebiasaan-kebiasaan
tradisional secara bertahap, termasuk
kebiasaan praktik kawin anum. Informan
ini menjadi perempuan satu-satunya yang
berpendidikan paling tinggi karena lebih
memilih kuliah. Duza dan Baldwin (1977)
menyatakan bahwa di negara-negara
yang sedang berkembang, perubahan dari
kebutaaksaraan secara massal menjadikan
penduduk yang dapat membaca dan menulis
mengakibatkan perubahan yang lebih
mencolok dibandingkan dengan perubahan
yang diharapkan, terutama dalam kaitannya
dengan umur perkawinan (Indonesia, 1980
dalam Kasto, 1982).

\section{b. Bekerja}

Faktor kedua yang memengaruhi perempuan keluar dari praktik kawin anum adalah bekerja. Perempuan yang bekerja, 3,1 kali lebih mampu keluar dari praktik kawin anum (Tabel 2). Faktor pengalaman bekerja menjadi salah satu faktor penundaan usia kawin pada perempuan. Para perempuan yang pernah bekerja sebelum kawin, rata-rata usia perkawinannya lebih tinggi dibandingkan dengan mereka yang tidak bekerja. Oleh sebab itu, keterlibatan perempuan dalam dunia kerja akan dapat menunda usia kawin pertama (Dixon, 1971;
Potts \& Selman, 1979; Abdurahman, 1987; Kasto, 1982; Sukamdi, Yuarsi dan Tamtiari 1995; Hanum, 1997; Jones, 2001). Mereka yang bekerja mempunyai rata-rata usia kawin yang lebih tinggi dibandingkan dengan yang tidak bekerja. Berikut adalah ungkapan dari informan perempuan yang keluar dari praktik kawin anum dengan cara bekerja.

“....imbah tuntung sakulah, mun bagana haja dirumah pacangan kada lawas dikawinakan. Mun sudah kawin nih susah mun handak becarian sorang, nyata dah tepatak dirumah meurus laki lawan anak. Baik sorang begawi, becari pengalaman banyak-banyak, puas-puasakan dulu tempulu anum, berbakti lawan kuitan hanyar kawin. Bila handak lakas beduit nyata dah pilihannya jadi TKW ke Arab. Bahari mikirnya mun pina nyaman kaina perpanjang kontrak, mun sakit bulik. Nang penting bejauh pada kampung anggaran kada lakas dikawinakan". (....setelah selesai sekolah, kalau berdiam saja dirumah tidak lama kemudian pasti dinikahkan. Kalau sudah menikah susah untuk menghidupi diri sendiri yang jelas dirumah mengabdi kepada suami dan anak. Lebih baik saya bekerja, benyakbenyak mencari pengalaman, dipuaskan dulu mumpun masih muda, berbakti kepada orang tua baru menikah. Jika ingin cepat memiliki uang pilihannya hanya menjadi TKW ke Arab. Dulu mikirnya kalau kerasan memperpanjang kotrak, jika tidak kerasan pulang. Yang penting meninggalkan kampung halaman supaya tidak cepat dinikahkan).

Perempuan yang bekerja, selain memiliki kemandirian ekonomi dan tidak tergantung secara finansial kepada keluarganya maupun 
orang lain, akan lebih memiliki kekuatan untuk mengatur hidupnya sendiri termasuk dalam menentukan kapan akan menikah. Di Kelurahan Raya Belanti, perempuan yang belum menikah di saat teman sebayanya sudah menikah dengan alasan sedang bekerja akan dimaklumi, baik perempun yang masih bekerja di Indonesia maupun menjadi migran internasional, karena daerah penelitian ini juga merupakan daerah kantong tenaga kerja wanita (TKW). Aktivitas seseorang mempunyai pengaruh terhadap peningkatan usia kawin (Sukamdi, Yuarsi dan Tamtiari, 1995).

\section{Interpersonal}

Status ekonomi rumah tangga asal perempuan dalam penelitian ini termasuk dalam variabel interpersonal. Status ekonomi rumah tangga asal perempuan yang tinggi 1,4 kali mampu mendorong perempuan keluar dari praktik kawin anum (Tabel .2). Tingkat ekonomi rumah tangga yang tinggi menghapus kerentanan anak, khususnya anak perempuan untuk dapat mengakses pendidikan yang lebih tinggi. Hal tersebut akan berdampak pada meningkatnya usia kawin pertama, atau dalam penelitian ini, mampu keluar dari praktik kawin anum.

\section{Societal}

Terkikisnya praktik kawin anum suku Banjar, salah satunya, dipengaruhi oleh faktor kebijakan pemerintah, yaitu perempuan yang menikah memenuhi syarat usia resmi minimal menikah sesuai Undang-Undang No.1 Tahun 1974 sebelum ada perubahan menjadi Undang-Undang Nomor 16 Tahun 2019 tentang Perkawinan pada pasal 7 ayat (1) yang berbunyi sebagai berikut.
"Perkawinan hanya diizinkan jika pihak pria sudah mencapai umur 19 (sembilan belas) tahun dan pihak wanita sudah mencapai umur 16 (enam belas) tahun“

Usia minimal legal menikah untuk perempuan menurut undang-undang adalah 16 tahun, sedangkan bagi perempuan yang ingin menikah sah secara undang-undang, harus memenuhi syarat minimal usianya di atas 16 tahun. Undang-undang tersebut pada tahun 2019 mengalami perubahan dan disahkan menjadi Undang-Undang Nomor 16 Tahun 2019 dengan syarat usia minimal legal menikah baik laki-laki maupun perempuan adalah 19 tahun. Perempuan yang keluar dari praktik kawin anum ketika menikah memenuhi syarat usia minimal yang ditentukan dalam undang-undang perkawinan.

Ada fenomena lain yang menjadi masalah tersendiri ketika usia calon pengantin tidak memenuhi syarat undang-undang perkawinan, yaitu mendaftarkan dispensasi perkawinan ke Pengadilan Agama atau menikah secara agama (nikah siri). Berikut adalah salah satu ungkapan dari perempuan yang keluar dari praktik kawin anum.

“... bahari tu pas ulun bekawinan, berataan sudah tuntung dibahas kaya jujuran, tanggal ijab. Dikira kadada halangan jadi beundangan ai sudah jua, mun dihitung umur ulun 16 jadi dipikir kadada masalah. Sakalinya 16 tahun kurang berapa hari kaitu, buhan KUA kada mau mengawinakan maraga umur balum hampai lagi jar. Paksa ae tatap beacara, ditatai sarabanya, naibnya lain orang KUA. Saminggu imbah tanggal ulang tahun ulun yang 16 hanyar kami nikah beasa di KUA anggaran dapat surat" (dulu waktu saya menikah, semua sudah selesai dibahas seperti jujuran, 
tanggal ijab, disangka tidak ada lagi masalah jadi menyebar undangan, kalau dihitung umur saya 16 dikira tidak ada masalah. Ternyata 16 tahun kurang berapa hari, pegawai KUA tidak mau menikahkan karena katanya umurnya belum sampai. Terpaksa tetap resepsi, dipajang juga, naibnya bukan dari KUA. Seminggu setelah tanggal ulang tahun saya ke 16 baru kami nikah ulang di KUA supaya mendapatkan surat nikah)

Ditemukan beberapa kasus perempuan yang tidak memenuhi syarat usia minimal legal menikah menurut undang-undang perkawinan memutuskan menikah siri atau menikah secara agama, bahkan tetap melakukan resepsi. Setelah usianya memenuhi syarat, mereka akan menikah ulang di KUA untuk mendapatkan akta nikah. Semua ini berhubungan dengan rendahnya pengetahuan tentang syarat usia resmi minimal perempuan dan laki-laki untuk diizinkan menikah serta pentingnya menikah resmi sesuai undang-undang negara.

\section{Institusional}

Petugas Pembantu Pencatat Nikah (P3N) di daerah penelitian yang juga merupakan tokoh agama mengimbau masyarakat bahwa jika ingin menikahkan anak perempuan, salah satu syaratnya adalah memiliki kartu tanda penduduk (KTP) atau telah berusia 17 tahun. Hal ini ternyata berdampak pada usia kawin pertama perempuan di daerah penelitian, yang terbukti dengan persentase tertinggi usia kawin pertama perempuan yang keluar dari praktik kawin anum suku Banjar berada di usia 17 tahun. Berikut adalah salah satu ungkapan dari P3N di Kelurahan Raya Belanti.
“... kami padahakan lawan buhannya, bila handak mengawinakan anaknya harus beisi KTP. Angaran tenyaman beurusan. Mun kada kaitu magin banyak lagi nang kawin anum Jadi buhannya wahini bila handak mengawinakan anaknya mehadang 17 tahun dulu. Wahini KTP kada kawa dinaikkan umurnya, apalagi e-KTP lok" (kami katakan pada mereka, bila ingin menikahkan anaknya harus memiliki KTP supaya lebih mudah mengurusnya. Jika tidak begitu, akan lebih banyak lagi yang menikah muda. Jadi mereka sekarang bila ingin menikahkan anaknya menunggu usia 17 tahun dulu. Sekarang KTP tidak bisa dinaikkan umurnya, apalagi e-KTP kan).

Pendapat dari pemangku kebijakan tentang usia resmi minimal perempuan untuk menikah berbeda dengan Undang-Undang Nomor 1 Tahun 1974 pasal 7, yaitu batas usia diizinkan menikah sekurang-kurangnya 16 tahun untuk pihak perempuan dan 19 tahun untuk pihak laki-laki. Di Kecamatan Binuang, diberitakan usia resmi minimal perempuan untuk menikah adalah 17 tahun. Hal tersebut berimbas pada pendewasaan usia kawin pertama, terutama perempuan yang ingin menikah resmi menurut undang-undang negara. Salah satu informan yang belum menikah berencana menikah di usia 17 tahun karena ingin menikah secara resmi dan memiliki akta nikah, tidak seperti teman sebayannya yang menikah siri dan tidak memiliki surat nikah.

“... wahini mun handak kawin umur harus hampai 17 tahun dulu lawan beisi KTP, hanyar dibariakan buhan KUA kawin, bilanya balum 17 tahun lawan balum beisi KTP paksa ae mehadang hampai umurnya. Kaina bila sudah hampai umurnya lakas meurus KTP, imbah itu kawa nikah di KUA, 
kawa beisi surat nikah. Ulun indah nikah siri kaya kekawanan ulun, bila basarakan kadada dapat apa-apa, akte anak bengaran mamanya wara, kasihan anak ulun kena" (sekarang ini apabila hendak menikah usia harus sudah 17 tahun dan memiliki KTP, baru diijinkan pegawai KUA menikah, jika usianya belum sampai 17 tahun dan belum memiliki KTP terpaksa menunggu hingga cukup usianya. Nanti bila usianya sudah cukup segera membuat KTP, setelah itu bisa menikah di KUA, bisa memiliki surat nikah. Saya tidak mau menikah siri seperti teman-teman saya, bila cerai tidak dapat apa-apa, akta anak hanya ada nama ibunya saja, kasihan anak saya nanti)

Di Kelurahan Raya Belanti terdapat 14 RT dengan 4 RT yang semua perempuannya merupakan pelaku praktik kawin anum, yaitu RT 11, 12, 13, dan 14. Disamping itu dari keempat RT tersebut tidak ada satupun penduduknya yang lulus SMP/sederajat. Salah satu informan perempuan yang diwawancarai mengungkapkan bahwa ia bercita-cita akan segera menikah jika telah ada yang melamar meskipun usianya baru 14 tahun.

\section{Kesimpulan}

Variabel yang memengaruhi perempuan keluar dari praktik kawin anum adalah individual (berpendidikan tinggi dan bekerja), interpersonal (tingkat ekonomi rumah tangga asal perempuan tinggi), institusional (syarat menikah memiliki KTP), dan societal (memenuhi syarat usia miminal resmi untuk menikah menurut Undang-Undang Perkawinan).

Teori utama yang digunakan untuk menjelaskan alasan perempuan keluar dari praktik kawin anum adalah teori
Social Ecological Framework (SEF). Lima variabel yang berpengaruh pada perilaku individu dalam teori SEF adalah individual, interpersonal, community, institusional, dan societal. Berdasarkan hasil penelitian dari lima variabel yang ada pada teori SEF, empat variabel yang menjadi faktor yang memengaruhi perempuan keluar dari praktik kawin anum adalah variabel individual, interpersonal, societal, dan istitusional.

Berdasarkan empat variabel yang memengaruhi perempuan keluar dari praktik kawin anum, variabel tersebut dibagi lagi menjadi dua aspek, yaitu aspek kultural dan aspek struktural. Aspek kultural yang berpengaruh adalah variabel individual dan interpersonal. Variabel individual yang menyebabkan perempuan keluar dari praktik kawin anum Suku Banjar adalah bekerja dan pendidikan. Sedangkan variabel interpersonal yang memengaruhi perempuan keluar dari praktik kawin anum Suku Banjar adalah status ekonomi rumah tangga asal perempuan. Aspek kultural yang berpengaruh aadalah variabel societal dan institusional. Variabel societal berkaitan dengan perempuan ketika menikah yang memenuhi syarat usia minimal resmi untuk menikah menurut Undang-Undang Perkawinan Nomor 1 Tahun 1974 sebelum direvisi menjadi Undang-Undang Nomor 16 Tahun 2019 dan variabel institusional berkaitan dengan pemberitahuan yang diberikan kepada penduduk bahwa salah satu syarat menikah adalah memiliki KTP.

Teori gender menjelaskan tentang bias yang terjadi pada usia minimal legal perempuan dan laki-laki diizinkan menikah sesuai Undang-Undang Nomor 1 Tahun 1974 tentang perkawinan tidak sama, dimana laki-laki diizinkan menikah minimal pada usia 19 tahun, sedangkan perempuan pada usia 16 tahun. Bias tersebut tentu 


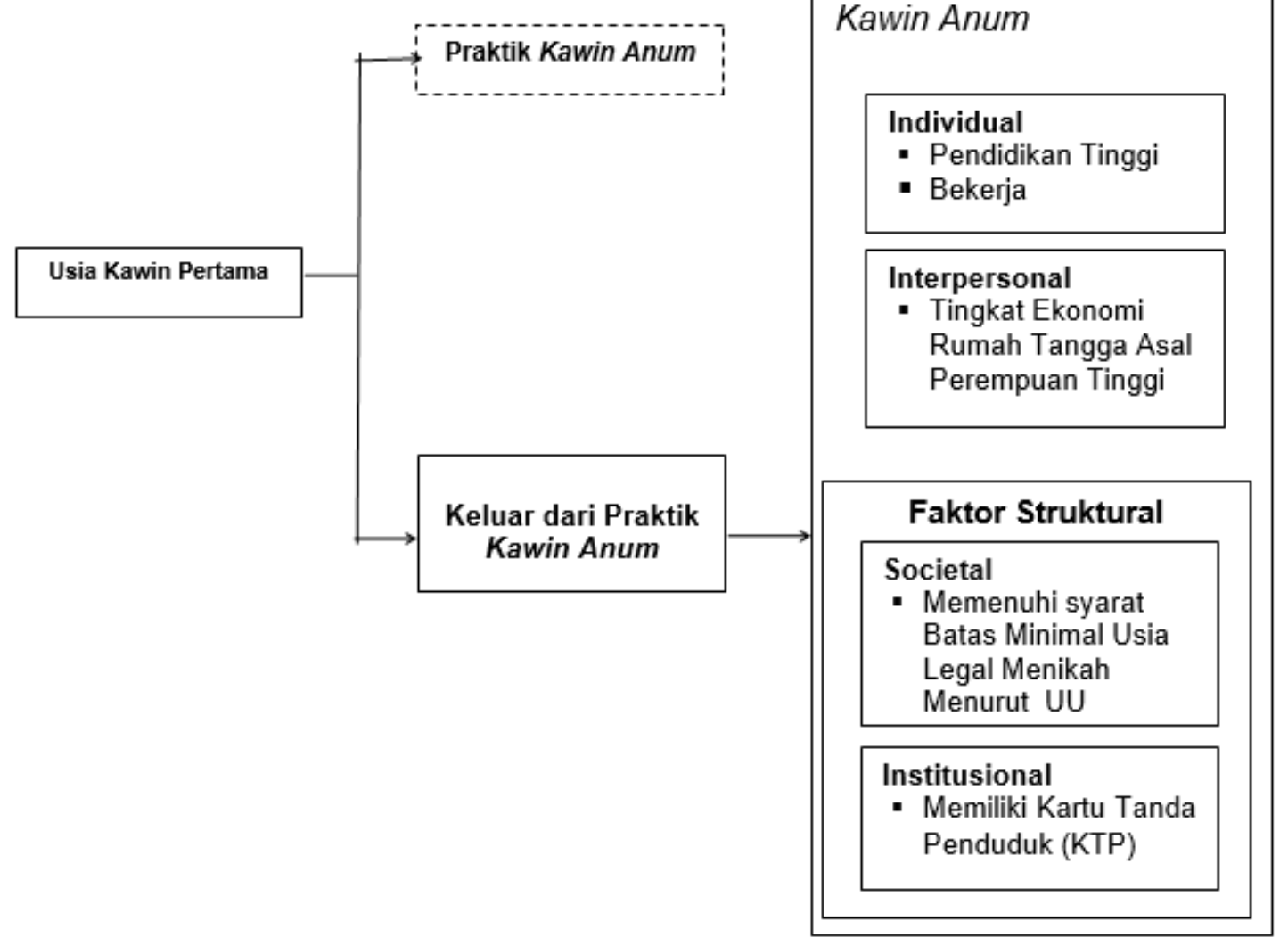

Faktor yang Menyebabkan Perempuan Keluar dari Kawin Anum

Individual

- Pendidikan Tinggi

- Bekerja

Interpersonal

Tingkat Ekonomi Rumah Tangga Asal Perempuan Tinggi

\section{Faktor Struktural}

Societa

Memenuhi syarat Batas Minimal Usia Legal Menikah Menurut UU

Institusional

Memiliki Kartu Tanda Penduduk (KTP)

Gambar 4. Hasil Analisis Determinan Perempuan Keluar dari

Praktik Kawin Anum Suku Banjar

saja berdampak pada kesehatan reproduksi bagi perempuan yang menikah berdasarkan usia minimal yang diizinkan undang-undang perkawinan. Belum lagi bias usia minimal resmi menikah berdampak pada pemenuhan hak di bidang pendidikan dan peluang dalam dunia kerja. Biar gender tentang batasan usia resmi minimal untuk menikah sudah tidak ditemukan, terhitung sejak 15 November 2019 dengan pengesahan Undang-Undang Nomor 16 Tahun 2019; perubahan atas Undang-Undang Nomor 1 Tahun 1974 tentang perkawinan pada pasal 7 bahwa perkawinan hanya diizinkan apabila laki-laki dan perempuan sudah mencapai 19 tahun.

\section{Daftar Pustaka}

Abdurahman, Edeng Halim. 1987. "Beberapa Faktor yang Mempengaruhi Pada Pola Perkawinan di Jawa Barat". Paper disajikan dalam Pertemuan IImiah Faktorfaktor Sosial, Budaya kaitannya dengan Pola Perkawinan. Bandung, Lembaga Penelitian UNPAD, 18 Juli 1987.

Badan Pusat Statistik and UNICEF. 2016. Kemajuan yang tertunda: Analisis Data Perkawinan Usia Anak di Indonesia. Jakarta: BPS.

Badan Pusat Statistik. 2017. Perkawinan Usia Anak di Indonesia 2013 dan 2015. Edisi Revisi. Jakarta: BPS. 
Choe, M.K, Shyam Thapa and Sulistinah Irawati Achmad. 2001. "Early Marriage and Chidbearing in Indonesia and Nepal". EastWest Center Working Papers. Population Series, No.108-15.

Duza dan Baldwin. 1977. Nuptiality and Population Study. New York: The Population Council.

PSKK UGM dan PLAN. 2011. Perkawinan Anak di Indonesia. Yogyakarta: PSKK UGM dan PLAN.

Creswell, John W. 2010. Research Design Pendekatan Kualitatif, Kuantitatif, dan Mixed. Yogyakarta: Pustaka Pelajar.

Dixon, Rugh B. 1971. Explaining cross culture variation in age at marriage and proportions never marrying. Population Studies, 25 (2): 215-233.

Hanum, Sri Handayani. 1997. Perkawinan Usia Belia. Kerjasama Pusat Penelitian Kependudukan Universitas Gadjah Mada dengan Ford Foundation. Yogyakarta: Universitas Gadjah Mada.

Indrayani dan Sjafii. 2012. Dampak Pendidikan Bagi Usia Pernikahan Dini dan Kemiskinan Keluarga. Gemari Edisi 143/Tahun XIII/ Desember 2012.

Jones. 2001. "The Demise of Universal Marriage in East and South-East Asia', in the continuing Demographic Transition, ed. Gavin W. Jones, Robert M. Douglas, John C. Caldwell and Rennie d'Souza, Oxford Clarendo Press 1997, pp. 51-79 cited in Jones, G. W., "Which Indonesia Women Marry Youngerst and Why?", 2001, Journal of Southeast Asian Studies, 32 (1), pp. 6778, February 2001. Printed in the United Kingdom, 2001 The National University of Singapore.

Kasto. 1982. Perkawinan dan Perceraian Pada Masyarakat Jawa. Yogyakarta: Pusat Penelitian dan Studi Kependudukan UGM.
Kementrian Pemberdayaan Perempuan dan Anak (KPPPA) dan BPS. 2018. Profil Anak Indonesia 2018. Jakarta: KPPPA.

Nasution, Rosramadhana. 2016. "Ketertindasan Perempuan Dalam Tradisi Kawin Anom" Subaltern Perempuan pada Suku Banjar dalam Perspektif Poskolonial. Yayasan Pustaka Obor Indonesia.

Potts, Malcolm and Peter Selman. 1979. Society and Fertility. London : Mac Donald and Evan.

Santhya, K. G., Ram, U., Acharya, R., Jejeebhoy, S. J., Ram, F. \& Singh, A. 2010. Associations between early marriage and young women's marital and reproductive health outcomes: evidence from India. International perspectives on sexual and reproductive health, 132-139.

Sukamdi, Susi Eja Yuarsi, and Wini Tamtiari. 1995. Tingkat, Pola dan Determinan Usia Kawin Wanita dan Pria. Journal Populasi Volume 6 Nomor 2. pp 55-77.

Utina, Ramli., Baderan, Dewi Wahyuni K., dan Pongoliu, Yayu Isyana. 2014. Kajian Faktor Sosial Ekonomi yang Berdampak pada Usia Perkawinan Pertama di Provinsi Gorontalo. Kerjasama BKKBN provinsi Gorontalo dengan IPADI provinsi Gorontalo.

Undang-Undang Republik Indonesia Nomor 1 tahun 1974 Tentang Perkawinan. Bandung: Citra Umbaran

Undang-Undang Republik Indonesia Nomor 16 Tahun 2019 Tentang Perkawinan. 